\title{
Cytochrome allelic variants and Clopidogrel metabolism in cardiovascular diseases therapy
}

\author{
Mohammed Jarrar, Shalini Behl, Ganiraju Manyam, Hany Ganah, Mohammed Nazir, Reem
}

Nasab and Khaled Moustafa*

\begin{abstract}
Clopidogrel and aspirin are among the most prescribed dual antiplatelet therapies used to treat the acute coronary syndrome (ACS) and heart attacks. However, their potential clinical impacts are a subject of intense debates. The therapeutic efficiency of clopidogrel is controlled by the actions of hepatic cytochrome P450 (CYPs) enzymes and impacted by individual genetic variations. Inter-individual polymorphisms in CYPs enzymes affect the metabolism of clopidogrel into its active metabolites and, therefore, modify its turnover and clinical outcome. So far, clinical trials fail to confirm higher or lower adverse cardiovascular effects in patients treated with combinations of clopidogrel and proton pump inhibitors, compared with clopidogrel alone. Such inconclusive findings may be due to genetic variations in the cytochromes CYP2C19 and CYP3A4/5. To investigate potential interactions/effects of these cytochromes and their allele variants on the treatment of acute coronary syndrome with clopidogrel alone or in combination with proton pump inhibitors, we analyze recent literature and discuss the potential impact of the cytochrome allelic variants on cardiovascular events and stent thrombosis treated with clopidogrel. The diversity of CYP2C19 polymorphisms and prevalence span within various ethnic groups, subpopulations and demographic areas are also debated.
\end{abstract}

Keywords: clopidogrel; CYP2C19; CYP3A4; proton pump inhibitors; cardiovascular events; acute coronary syndrome; biodrugs; clopidogrel metabolism.

\section{1) Introduction}

Ischemic heart diseases, stroke, lower respiratory infections and chronic obstructive lung diseases are major health issues worldwide. According to a recent fact sheet on cardiovascular diseases (CVDs), about 17.5 million people (31\% of all global deaths) have died from (CVDs) in 2012 [1]]. Among them, about 7.4 million people died from coronary heart disease and 6.7 million from strokes [1]. To reduce heart attacks, clopidogrel with aspirin are among the most common medication prescribed to treat the acute coronary syndrome (ACS). Although other medications such as prasugrel and ticagrelor are fasteracting with more potent and consistent antiplatelet effects than clopidogrel, they are associated with more bleeding risks [2] . Clopidogrel is a class of thienopyridine antiplatelet 
agent used to inhibit blood clots. The prescription of antiplatelet agents, such as clopidogrel, has indeed become a stronghold of atherosclerotic cardiovascular disease therapy [ $\underline{3}$ ]. The joint guideline of the American College of Cardiology/American Heart Association recommends clopidogrel and aspirin as a standard treatment of the acute coronary syndrome [4]. This dual antiplatelet therapy reduces the risk of recurrent ACS compared with aspirin alone. It also helps preventing other health troubles such as stent thrombosis in patients undergoing percutaneous interventions. The international prevalence of aspirin and other antiplatelet prescriptions is estimated at about 60 and $25 \%$, respectively []ㅡ, although these estimates vary widely and are influenced largely by age, sex, and obesity. For example, physicians prescribed aspirin and other antiplatelet medications significantly more often when a patient had hyperlipidemia or ischemic heart disease. Cardiologists often prescribed aspirin and other antiplatelet medications at $68 \%$ of visits; almost twice the times when compared with primary care specialists [6]. On another hand, in 2011-2012, one-third of U.S. adults aged $\geq 40$ years reported taking preventive aspirin and/or other antiplatelet medications, $97 \%$ of whom indicated preventive aspirin use, which seems to increase with age (from $11 \%$ for people aged $40-49$ years to $54 \%$ of those $\geq 80$ years old [7]. In the United States, about $13 \%$ of patients with coronary heart disease are prescribed a dual antiplatelet therapy of aspirin and clopidogrel [] [ [9]. In fact, the use of thienopyridines, such as clopidogrel in combination with aspirin, delays the death and reduces the myocardial infarction rates by $77 \%$ compared with aspirin alone [10].

There is an expanding number of databases and evidences on the genetic polymorphism's effects on the metabolism of clopidogrel and its clinical outcomes. To explore poor metabolizers related to the cytochromes genes CYP2C19, CYP3A4 and CYP3A5 and their allelic variants in specific populations, we analyzed the scientific literature using the key words mentioned above, and analyzed the 1000 genomes' dataset (1000 genomes project consortium [11] http://www.1000genomes.org). The analysis was carried out by dividing the populations into groups and sub groups. The allele frequencies at various genomic loci for genes were extracted from the 1000 genomes datasheet. Perl scripts, a scripting language of choice for hundreds of CGI scripts (https://www.perl.org/), were used to summarize the allele's frequencies across the populations based on the geographic location. The allele's frequency of the gene CYP2C19 was found particularly divergent across specific geographic locations.

\section{2) Mechanism of action and metabolism of Clopidogrel}

Clopidogrel is a prodrug, administered in a pharmacologically inactive form that needs to be metabolized to produce an anti-aggregating effect through active metabolites [12]. The activation of clopidogrel takes place in the liver under the action of cytochrome P450 (CYPs) enzymes that produce the active thiol metabolites that in turn bind to, and inactivate, the ADP P2Y12 receptor on the platelets' surface [Fig 1]. The metabolism of clopidogrel involves 2 successive steps; each of them is catalyzed by different members of the cytochrome P450 


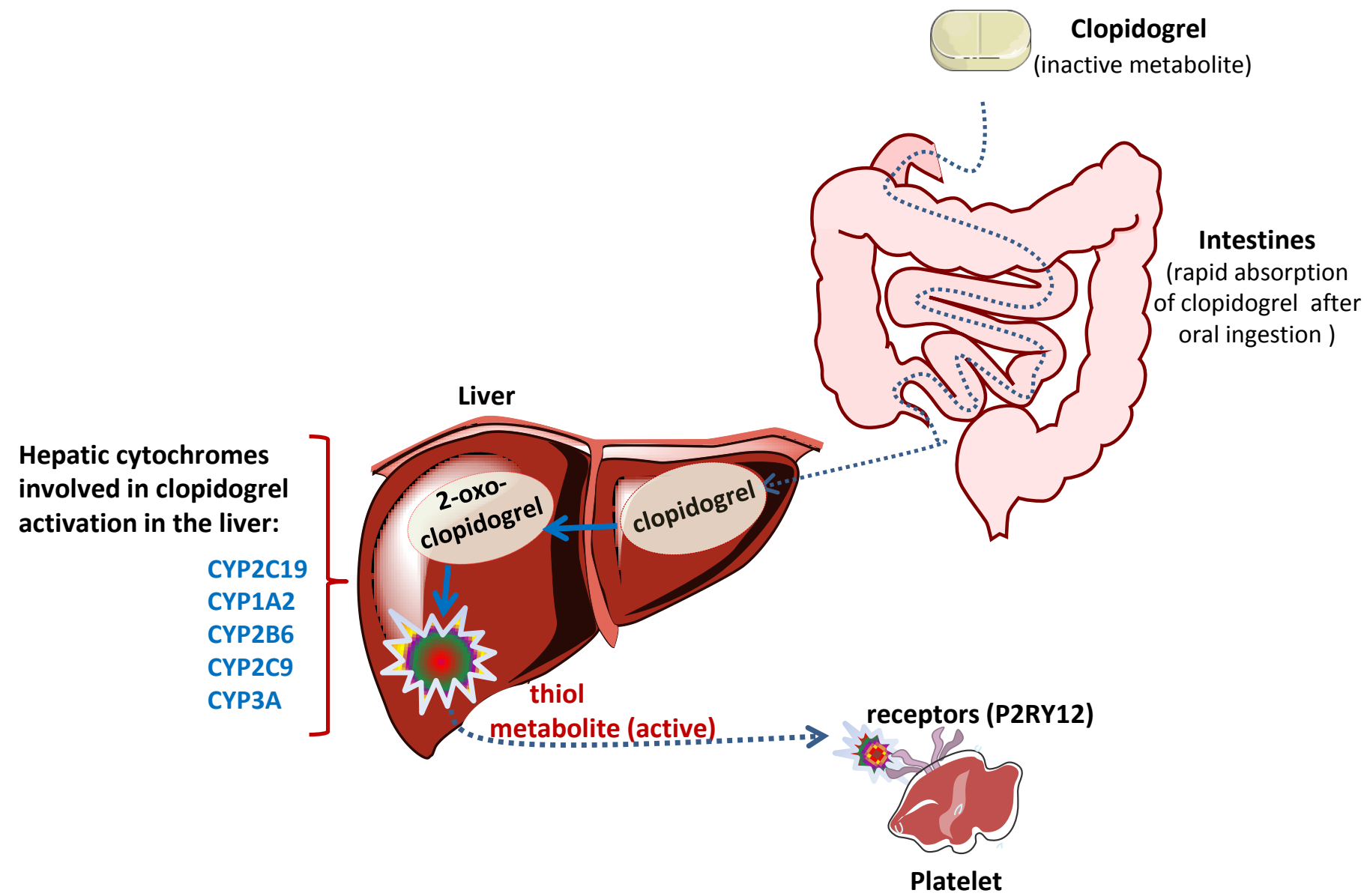

Fig 1. Activation and mechanism of action of clopidogrel. After absorption, the clopidogrel (inactive) is oxidized to 2-oxo clopidogrel (still inactive, too) by cytochrome P450 (CYP) enzymes in the liver. The 2-oxo clopidogrel is then transformed into active thiol metabolites that will bind to, and inhibit, the ADP P2RY12 receptor (adenosine diphosphate purinergic receptor P2Y G protein-coupled 12) on platelet surfaces. The inhibition of $\mathrm{P} 2 \mathrm{RY} 12$ receptors will then reduce platelet aggregation rates. 
(CYP) members. The first step is an oxidation phase catalyzed by the cytochromes CYP2C19, CYP1A2 and CYP2B6, converting the clopidogrel into 2-oxo-clopidogrel [13] [14]. The second step is catalyzed by the cytochromes CYP3A4/5, CYP2B6, CYP2C19 and CYP2C9 to produce the active form of the clopidogrel [15]. The active metabolite is then transported into the blood circulation where it binds to the adenosine diphosphate (ADP) receptor on the surface of platelets, preventing the activation of glycoprotein Ilb/Illa pathway, and thus, reducing platelet aggregation (clopidogrel has an anti-aggregating property) [1].

\section{3) Allelic distribution and Clopidogrel Responsiveness on Clinical Efficacy of CYP2C19}

The human cytochromes CYP2Cs are a key subfamily of the cytochrome P450 enzymes that metabolize about $20 \%$ of the therapeutic agents currently used in clinical trials [17]. Some members of this subfamily are highly polymorphic, such as the cytochrome CYP2C19, located on the chromosome 10 (locus 10q24.1-q24.3), and considered as one of the most polymorphic CYP genes [18] [19] with more than 33 genetic variants identified so far (http://www.cypalleles.ki.se/cyp2c19.htm), although many of them are rare. A new CYP2C19 variant, named cyp2c19*34, has recently been identified in a patient with adverse reactions towards venlafaxine monotherapy and dual therapy with nortriptyline and fluoxetine [20].

The efficacy of treatment with clopidogrel is affected by CYPs activities which, in turn, impacted by genetic variations. For example, the Cytochrome P450 2C19 polymorphism is associated with a poor clinical outcome in patients with coronary artery disease treated with clopidogrel [21]. The cytochrome variants CYP2C19*2 (G681A) and CYP2C19*3 (G636A), different from the active variant CYP2C19*1 by one single nucleotide only, are also considered as poor metabolizers characterized by a loss or severely decreased enzyme activity. By contrast, the CYP2C19*17 allele (c.-806C>T; rs12248560), characterized by an enhanced enzymatic activity, is categorized as an ultra-rapid metabolizers.

Several population studies have been carried out to identify the frequency and distribution of cytochrome alleles among different ethnic groups. The CYP2C19*2 allele was found more frequently and variants in Asian populations ( $30 \%)$ than in African-Americans ( $18 \%$ ) or Caucasians ( 13\%). The CYP2C19*3 allele is also more frequent in Asian populations ( $10 \%)$ compared with other racial groups (<1\%) [22]. In contrast, the CYP2C19*17 allele is common among Caucasians and Ethiopians (18\%), but relatively rare among Asians (4\%) [23]. The alleles CYP2C19*4, ${ }^{*} 5, * 6.7$ and $* 8$ are also less frequent in the general population but associated with a reduced metabolism [24].

The 1000 genomes' dataset was used to explore whether specific populations are enriched for the poor metabolizers of CYP2C19 variants (mainly CYP2C19*2 and CYP2C19*3). Although it was already known that these poorly metabolizing alleles are more common in Asia, they seem to be more specific and prevalent in some populations within Asia. The allele CYP2C19*3 is particularly prevalent in North Asian populations compared to South Asians 
while CYP2C19*2 is more common in South Asian populations. In South Indian Telugu and Srilankan Tamil populations, the CYP2C19*2 is frequent at $64.09 \%$ and $59.22 \%$, respectively (Table 1). This is further supported by a recent study in South Indian populations suggesting that about $71 \%$ of patients have at least one CYP2C19*2 allele [25].

Similarly, Table 2 summarizes the ethnic distribution of the allele CYP2C19*2B (this name was attributed to differentiate it from the original splice variant, renamed as CYP2C19*2A). The CYP2C19*2B allele variant has two mutations; the first is in exon 2, resulting in a coding change Glu923Asp that was identified in a single Swiss Caucasian family as a poor metabolizer for the anticonvulsant drug S-mephenytoin, and the second mutation is located in exon 5. The allele (CYP2C19*2B) seems to be present in European populations, particularly in England, Scotland and Finland (Table 2), which is in agreement with previous studies [26].

\section{4) Interaction between CYP2C19 and its alleles on cardiovascular events or stent thrombosis}

The allele CYP2C19*1 is a wild-type version of the cytochrome CYP2C19 with a full enzymatic activity whereas the variants CYP2C19*2 and CYP2C19*3 are poor metabolizer alleles [27]. Large volumes of clinical studies from various ethnic populations worldwide demonstrate an association between the genotype CYP2C19 allelic variants and the metabolism of clopidogrel and platelet aggregation. These studies are reviewed and summarized in Table 3. However, a few studies suggest that no significant interactions would exist between CYP2C19 and clopidogrel therapy on cardiovascular events. Out of the total studies mentioned in Table 3, six of them are randomized trials while the others are Treatment-Only Studies (all individuals are treated with clopidogrel with varying loading and maintenance doses).

\section{5) Allelic distribution and clopidogrel responsiveness on clinical efficacy of CYP3A4/5}

The cytochrome CYP3A subfamily is involved in the metabolism of more than $60 \%$ of the known therapeutic agents [28] [29]. CYP3A4 and CYP3A5 share 85\% sequence identity and display similar substrate affinities. CYP3A4 is abundant in the human liver with 40 allelic variants. CYP3A5, on the other hand, is a primary extra hepatic CYP3A enzyme with more than 25 allelic variants (http://www.cypalleles.ki.se/cyp3A5.htm). Ethnic distributions of CYP3A4/5 alleles are summarized in Table 4.

CYP3A4/5 are involved in the oxidation of clopidogrel to produce 2-oxo-clopidogrel prior to the production of the active thiol metabolite. As a result of our "1000 genomes analysis" on CYP3A4 and CYP3A5; there was no interesting patterns as we saw in CYP2C19, only CYP3A5*3 has some substantial number of alleles of interest (Table 5). 


\section{6) Interaction between CYP3A4/3A5 and its alleles on major cardiovascular events or stent thrombosis}

Data from clinical studies on CYP3A4/5 enzymes (Table 6) reported contradictory results on the association of these enzymes and the clinical efficacy of clopidogrel. Among 9 clinical studies, five of them suggest a clinical significance of the CYP3A4/5 genotype in the assessment of the risk of cardiovascular events among patients treated with clopidogrel, while the remaining 4 studies show no association of CYP3A4/5 genotype in determining the clinical responsiveness to clopidogrel.

Different studies confirm the role of CYP3A4/3A5 in the metabolism of a wide range of drugs, such as immune-suppressants, cancer chemotherapeutic agents, calcium channel blockers, and synthetic estrogens. Some endogenous steroids such as the cortisol, testosterone, estradiol, and some harmful dietary contaminants can also be metabolized by the allele CYP3A4/3A5 [30] [31]

In clearance of CYP3A substrates, the CYP3A5 polymorphic expression may account for some inter-individual variations [32]. In kidney and lung transplant recipients, CYP3A5 genotype was shown to be as a predictive of tacrolimus doses [33] [34]. The CYP3A5 allele expressers require higher doses of tacrolimus and have lower concentration/dose ratios [35].

On another hand, most studies showed an association between CYP3A5 genotype variants and clopidogrel responsiveness. Park et al. 2012, for example, concluded that CYP3A5 genetic status plays an important role in the clinical efficacy of clopidogrel in a prospective cohort study involved 1258 Caucasian patients; out of which the wild type number was 509 and the variant CYP3A5*3 was 749 [36]. Among the Tamil population, it was found that a single nucleotide polymorphism (SNP) of the cytochrome CYP3A5*3 contributes to clopidogrel resistance [37].

Another clinical study to explore the influence of CYP3A5 polymorphism on drug interaction in patients administered with clopidogrel was conducted by Suh et al. in two phases [38]. In phase 1 , clopidogrel was administered to 16 healthy volunteers with the allele CYP $3 A 5^{*} 3$ and 16 others with the allele CYP3A5*1 with or without pre-treatment with itraconazole (a potent CYP3A inhibitor). A platelet aggregation test was then performed after clopidogrel administration at the interval of 4 hours, 24 hours and 6 days. In phase 2, the clinical outcomes of 348 patients treated with clopidogrel after a successful coronary angioplasty was compared with bare-metal stent implantation. The main end point was a combination of antherothrombotic events (myocardial infarction, non-hemorrhagic stroke and cardiovascular death) within 1 and 6 months after stent implantation. The study concludes that the change in platelet aggregation was greater among subjects with CYP3A5 expresser genotypes than among non-expresser genotypes [38]. In another study of 22 healthy Korean subjects ( 16 subjects with CYP3A5*3, and 6 with the wild type version), it was found that the CYP3A5*3 genotype is a contributor of inter-individual variability of clopidogrel efficacy and 
its antiplatelet effects [39]. By contrast, in a study of 45 Egyptian patients (44 subjects with CYP3A5*3), it was reported that CYP3A5 genetic polymorphism does not seem to be contributing in the observed variability of the inhibitory effect of clopidogrel [40].

The role of CYP3A4/5 in the metabolism and bioactivation of clopidogrel was previously discussed by Zhu \& Zhou 2012 [41]. More specifically, CYP3A4/5 is responsible for metabolizing the piperidine motif in the clopidogrel, leading to a heavy metabolic attrition and pro-drug activation. The inhibition of CYP3A4/5-mediated attrition was shown to potentiate the formation of the clopidogrel active metabolite [41]. Such finding underestimates the fact that CYP2C19 and genetic polymorphism is not the only determinant of clopidogrel efficacy as well as the metabolism of other drugs. Cooperative and complementary roles of many CYP enzymes, in addition to genetic polymorphism and allelic variations further complicate the comprehension of their role in drug efficiency.

\section{7) Co-administration and interaction of Clopidogrel and proton pump inhibitors}

Proton pump inhibitors (PPIs) are among the most widely prescribed medications with about 12.4 million prescriptions issued in Canada alone in 2004 (Canadian Agency for Drugs and Technologies in health, 2008). So far, five different PPIs (namely omeprazole, esomeprazole, lansoprazole, pantoprazole and rabeprazole) are commonly marketed for medical uses. PPIs are benzimidazole derivatives composed of two heterocyclic parts interconnected by a methylsulfinyl group [42]. As weak bases, the two groups cross the cell membrane and accumulate in the highly acidic canalicular space. After a protonation process of two-steps, the drug reacts with a cysteine sulfhydryl on the gastric $\mathrm{H}+\mathrm{K}+-$ ATPase and forms covalent disulfide bonds that inhibit its activity [43] [44].

The prescription of anti-platelet agents such as the clopidogrel (with or without aspirin) is a backbone of the atherosclerotic cardiovascular disease therapy. However, the mono- or dual prescription option is subjective to the high risk of gastrointestinal hemorrhage, peptic ulceration, perforation and obstruction [] [ [45]. The largest study done so far for patients treated with clopidogrel concluded that, clopidogrel use is associated with an increased risk of adverse gastrointestinal (GI) events such as gastritis, ulcers and bleeding, suggesting that the benefits of clopidogrel should be weighed up against an increased $\mathrm{Gl}$ adverse risks [46]. However, given the risks of morbidity and death in patients on dual antiplatelet therapy, an expert consensus board recommends the use of proton pump inhibitors in dual antiplatelet therapy in patients who have higher risk factors for gastrointestinal bleeding [47] [9]. In fact, about $13 \%$ of patients with coronary artery disease in the United States are prescribed an aspirin and clopidogrel dual antiplatelet therapy [8]

Proton-pump inhibitors (PPIs) are believed to decrease the risk of such complications of gastrointestinal bleeding in patients receiving dual antiplatelet therapy. The results of the COGENT trial [48]; a prospective, randomized, placebo-controlled trial of omeprazole in patients receiving aspirin and clopidogrel concluded that prophylactic use of a PPI reduces the rate of upper gastrointestinal bleeding. There was no apparent cardiovascular 
interaction between clopidogrel and omeprazole, nevertheless the results do not rule out a clinically meaningful difference in cardiovascular events due to the use of a PPI [48].

Several studies suggest that most PPIs competitively inhibit the metabolism of clopidogrel. For example, Juurlink et al. (2009) report that proton pump inhibitors, especially omeprazole, reduce the beneficial effects of clopidogrel and increase the risk of reinfarction [49]. Other pharmacodynamics studies suggest an interaction of clopidogrel with proton pump inhibitors, whereas clinical evidence based on nonrandomized and observational studies is still conflicting [50]. Out of twelve clinical studies (Table 7) with a total of 183,739 patients, five of them with a total of 98,502 patients, report an interaction between PPIs and clopidogrel. This interaction reduces the efficacy of clopidogrel and results in a consecutive increase in adverse cardiovascular events. Given that some of them are multicenter blind trials, such studies would have more weight than retrospective studies seen found as "negative-interactions". In contrast, 7 retrospective studies with a total of 85,237 patients do not show any clopidogrel-PPI interactions, suggesting that PPIs do not interfere with the metabolism of clopidogrel and, therefore, do not contribute to any adverse outcomes.

The impaired antiplatelet activity in some patients treated with PPI and clopidogrel can be explained by two hypotheses [9]. The first assumes that the biological activity of clopidogrel is reduced. In fact, one of the key isoenzymes required for its conversion is the CYP2C19 enzyme, which is also required for the metabolism of all PPIs [51] [9 $]$. Thus, a competitive inhibition of this isoenzyme is likely to reduce the production of clopidogrel active thiol metabolite [52] [9]. Early observational studies, on another hand, failed to confirm any deleterious effect of the co-prescription of clopidogrel with PPI inhibitors [49] [9]].

Another explanation of the impairment of antiplatelet activity is the genetic variation that affects the metabolism of both drugs. Both clopidogrel and PPIs (e.g. omeprazole) are metabolized by CYP2C19 and CYP3A4 enzymes. Consequently, a loss-of-function mutation in the CYP2C19 seems to be associated with a less active clopidogrel metabolite and a higher risk of cardiovascular events [두] [9] [두].

Whether pharmacological interactions between clopidogrel and PPI adversely influence their clinical efficacy is still controversial [51]. However, based on a largely post-hoc analysis, the combinations of PPIs (such as esomeprazole, lansoprazole, omeprazole, pantoprazole, rabeprazole) and thienopyridine or aspirin-based therapy reduce the incidence of gastrointestinal bleeding compared with either agent administered without a PPI [51]. Most PPIs are widely metabolized by, and competitively inhibit, CYP2C19 and CYP3A4 [55]. Lansoprazole and omeprazole appear to be among the strongest inhibitors of CYP2C19, whereas the pantoprazole is among the weakest.

Another study measuring the half maximal inhibitory concentration (IC50) values of different PPIs in human liver microsomes suggests that lansoprazole and omeprazole exert inhibitory effects on clopidogrel antiplatelet activity [56], although the inhibitory effects depend on each PPI individually. 
An expert position paper published recently [ㄷ]], comprehensively reviewed the potential interactions and consequences of the use of proton pump inhibitors in patients with cardiovascular disease regarding antithrombotic activity and measurements of platelet function was inconclusive of the clinical efficacy. Pharmacodynamic studies favored the treatments with the use of newer PPIs that have less CYP2C19 inhibitory capacity (e.g., pantoprazole) than a PPI with high CYP2C19 inhibitory capacity (e.g., omeprazole) [57]. Since most currently available clinical outcomes data are mainly derived from retrospective studies, including registries, and therefore, confounding conclusions cannot be excluded; PPIs may represent a marker of cardiovascular risk rather than the cause of reduced efficacy of antithrombotic drugs. Given the large number of patients treated with PPIs and antithrombotic drugs, even a minor reduction in the cardiovascular benefits of antithrombotic drugs may still have substantial clinical impact. Accordingly, more studies are needed to elucidate the clinical importance of such drug interactions [57].

Finally, in the dual antiplatelet therapy of clopidogrel and aspirin, the observed interaction between clopidogrel and PPIs and the possible corresponding clinical effects may be explained, at least partially, by an interaction between the aspirin and PPIs. The tendency of individual PPIs to interact with other drugs varies. For example, omeprazole has higher affinity for CYP2C19 while a moderate affinity for CYP3A4. The possible interaction of such PPI with aspirin may also affect its affinity to the CYP2C19 and CYP3A4 differentially and consequently could influence their interaction with clopidogrel. Laboratory measurements of platelet aggregation in patients treated with aspirin and a PPI compared to patients treated with aspirin only, has been shown to be increased. Similarly, platelet activation assessed by soluble P-selectin was higher in patients treated with aspirin and a PPI [58]. Still, it is uncertain whether the observed reduced or increased platelet aggregation or activation ex vivo has any clinical effect on cardiovascular risk [두].

Furthermore, clinically supportive evidence came as a result of the Danish retrospective study that is based on information from national registers. It showed that in aspirin treated patients with first time myocardial infarction, treatment with PPIs was associated with an increased risk of adverse cardiovascular events. Possible explanations for such adverse cardiovascular events could be referred to one or more of the following: modification of intragastric $\mathrm{pH}$ causing reduced bioavailability of aspirin and so increased platelet aggregation and platelet activation; proton pump inhibitors itself altering in an unknown way a physiological or biological pathway; or due to unmeasured differences in baseline comorbidities [59]. Selection biases and a generalization of these data to other racial and ethnic groups could be drawbacks.

\section{8) Conclusion and Perspective}

Better understanding of drug-drug interactions in clopidogrel and PPIs linked to the metabolic efficiency of CYP2C19 alleles would have better health outcomes in treatment and prognosis of cardiovascular diseases. The importance of genotyping of CYP2C19, particularly 
in patients with CAD, before undergoing clopidogrel treatments, becomes closer to the epic of personal translational therapy than ever. This would help to identify patients who are unlikely to benefit from clopidogrel-based treatments and then to look for alternatives or dose regime adjustments.

Assessments of clinical outcomes of any combination treatment should be assessed based on the tangible clinical outcomes and then experimentally on enzymatic and metabolic level in laboratory. As drug-drug interactions became more complicated and have dramatic influences on drug efficacy and health complications, PPI type, necessity and doses of prescriptions should be carefully evaluated. This review indirectly reflects on the possible impacts on the cost, barriers and obstacles for better management and health of CVD.

However, individual variability in clopidogrel-induced antiplatelet effects due to genetic variations in CYP2C19 and CYP3A4/5 remain elusive. For consolidation of evidences for such possibilities, there are many new ongoing trials to clarify and narrow the debate. For instance, searching for ongoing clinical trials related to CYP2C19 polymorphism genotyping and treatment with clopidogrel from Clinical Trials' website (https://www.clinicaltrials.gov) revealed that 22 are currently recruiting or will be recruiting participants soon. Most of ongoing studies are interventional randomized trials. Six of these trials are investigating the possible role of CYP2C19 polymorphism and interactions of Clopidogrel combined treatment with PPIs.

Although there is a possible competitive effect of PPIs on the CYP2C19, it is still unclear whether the level of interaction between the clopidogrel and PPIs is due to specific PPIs or it represents a general class effect [60]. One of the currently recruiting trials is an observational type with a case-crossover perspective design to determine whether the interaction between proton-pump inhibitor, omeprazole, and clopidogrel is dependent on CYP2C19 haplotype. Another phase 3 study comparing the efficacy and safety of prasugrel and clopidogrel in acute coronary syndrome patients with CYP2C19 polymorphism who undergo percutaneous coronary intervention (PRAISE-GENE). The purpose of this study is to determine whether reduced loading dose of prasugrel followed by reduced maintenance dose of prasugrel in acute coronary syndrome patients with CYP2C19 polymorphism undergoing percutaneous coronary intervention might exhibit lower platelet reactivity 24 hours and 30 days later.

The distribution of poor metabolizing alleles of CYP2C19 across various geographically ethnic groups is diverse, and so possibly the clinical efficacy of clopidogrel. The allele CYP2C19*3 is more prevalent in North Asian populations compared to South Asians. Conversely, the CYP2C19*2, seems to be more frequent in South Asian populations compared to North Asians. The allele CYP2C19*2B, identified in Caucasians and localized to European populations, is particular to English, Scottish and Finish populations. A genetic screening of more ethnic groups and sub-populations for allelic variants and mutations in CYP genes would further enrich and expand the significance as well as the value of the Human Genetic 
Variations Project. Genetic screening is the first step for the implementation of individualized therapy of genetic diseases. For such purpose there is an ongoing study called "a bedside testing of the CYP2C19 gene (allele 2 or 3) to assess the effectiveness of clopidogrel in CAD patients treated with percutaneous coronary intervention; tailored and individualized antiplatelet drug treatment to improve prognosis". Another currently recruiting trial is an interventional study of clopidogrel and ticagrelor antiplatelet treatment using an individualized strategy base by genotyping of CYP2C19*2 in Chinese patients with ACS.

Good Drug design and bioinformatics tools could also be helpful to design efficient drugs based on allelic variations in CVD patients.

In wrapping up, the paradox of whether to co-prescribe an antiplatelet agent, such as the clopidogrel with or without aspirin, and with or without PPI for the atherosclerotic cardiovascular disease therapy is still open. Although the effect of CYP2C19 and CYP3A4/5 on the clinical efficacy of clopidogrel still under debate, new variants may shift the balance towards one side or another, and clinicians may need to genotype patients for cytochrome allelic variants for a better treatment.

Meanwhile, more evidences are needed to disapprove the use of concomitant therapy of clopidogrel with proton pump inhibitors by further research and clinical trials. Yet, to minimize potential adverse interactions, co-prescriptions of clopidogrel and different PPIs at different concentrations and different intervals might be considered. The exploration of new PPIs of different metabolism pathways (such as rabeprazole) that would not interfere with the metabolism of clopidogrel and the use of active forms of clopidogrel and PPIs directly either by injection or by new technologies such as nanotechnology and encapsulation might be worth considering.

\section{Disclosure: None}

\section{9) References}

1. World Health Organization. Cardiovascular diseases (CVDs) Fact sheet $N^{\circ} 317.2015$; Available from: http://www.who.int/mediacentre/factsheets/fs317/en/.

2. Grove, E.L., et al., Antiplatelet therapy in acute coronary syndromes. Expert Opin Pharmacother, 2015. 16(14): p. 2133-47.

3. Abraham, N.S., Prescribing proton pump inhibitor and clopidogrel together: current state of recommendations. Curr Opin Gastroenterol, 2011. 27(6): p. 558-64.

4. Antman, E.M., et al., ACC/AHA Guidelines for the Management of Patients With ST-Elevation Myocardial Infarction-Executive Summary: A Report of the American College of Cardiology/American Heart Association Task Force on Practice Guidelines (Writing Committee to Revise the 1999 Guidelines for the Management of Patients With Acute Myocardial Infarction). Circulation, 2004. 110(5): p. 588-636. 
5. Bhatt, D.L., et al., Clopidogrel and aspirin versus aspirin alone for the prevention of atherothrombotic events. N Engl J Med, 2006. 354(16): p. 1706-17.

6. George, M.G., et al., Recommended use of aspirin and other antiplatelet medications among adults-National Ambulatory Medical Care Survey and National Hospital Ambulatory Medical Care Survey, United States, 2005-2008. MMWR Morb Mortal Wkly Rep, 2012. 61(1).

7. Gu, Q., et al., Preventive Aspirin and Other Antiplatelet Medication Use Among US Adults Aged $\geq 40$ Years: Data from the National Health and Nutrition Examination Survey, 20112012. Public health reports (Washington, DC: 1974), 2014. 130(6): p. 643-654.

8. Cannon, C.P., et al., Current Use of Aspirin and Antithrombotic Agents in the United States Among Outpatients With Atherothrombotic Disease (from the REduction of Atherothrombosis for Continued Health [REACH] Registry). American Journal of Cardiology, 2010. 105(4): p. 445452.

9. Abraham, N.S., et al., ACCF/ACG/AHA 2010 Expert Consensus Document on the Concomitant Use of Proton Pump Inhibitors and Thienopyridines: A Focused Update of the ACCF/ACG/AHA 2008 Expert Consensus Document on Reducing the Gastrointestinal Risks of Antiplatelet Therapy and NSAID Use: A Report of the American College of Cardiology Foundation Task Force on Expert Consensus Documents. Circulation, 2010. 122(24): p. 2619-2633.

10. Yusuf, S., et al., Effects of clopidogrel in addition to aspirin in patients with acute coronary syndromes without ST-segment elevation. N Engl J Med, 2001. 345(7): p. 494-502.

11. Genomes Project, C., et al., An integrated map of genetic variation from 1,092 human genomes. Nature, 2012. 491(7422): p. 56-65.

12. Savi, P., et al., The antiaggregating activity of clopidogrel is due to a metabolic activation by the hepatic cytochrome P450-1A. Thromb Haemost, 1994. 72(2): p. 313-7.

13. Kazui, M., et al., Identification of the human cytochrome P450 enzymes involved in the two oxidative steps in the bioactivation of clopidogrel to its pharmacologically active metabolite. Drug Metab Dispos, 2010. 38(1): p. 92-9.

14. Savi, P., et al., Identification and biological activity of the active metabolite of clopidogrel. Thromb Haemost, 2000. 84(5): p. 891-6.

15. Kazui, M., et al., Identification of the Human Cytochrome P450 Enzymes Involved in the Two Oxidative Steps in the Bioactivation of Clopidogrel to Its Pharmacologically Active Metabolite. Drug Metabolism and Disposition, 2010. 38(1): p. 92-99.

16. Anderson, C.D., et al., Personalized Approaches to Clopidogrel Therapy: Are We There Yet? Stroke, 2010. 41(12): p. 2997-3002.

17. Goldstein, J.A., Clinical relevance of genetic polymorphisms in the human CYP2C subfamily. $\mathrm{Br}$ J Clin Pharmacol, 2001. 52(4): p. 349-55.

18. Bertilsson, L., Geographical/interracial differences in polymorphic drug oxidation. Current state of knowledge of cytochromes P450 (CYP) 2D6 and 2C19. Clin Pharmacokinet, 1995. 29(3): p. 192-209.

19. Ghodke, Y., et al., Genetic polymorphism of CYP2C19 in Maharashtrian population. Eur J Epidemiol, 2007. 22(12): p. 907-15.

20. Chua, E.W., et al., Novel CYP2D6 and CYP2C19 variants identified in a patient with adverse reactions towards venlafaxine monotherapy and dual therapy with nortriptyline and fluoxetine. Pharmacogenet Genomics, 2013. 23(9): p. 494-7.

21. Jin, B., et al., Cytochrome P450 2C19 polymorphism is associated with poor clinical outcomes in coronary artery disease patients treated with clopidogrel. Molecular Biology Reports, 2011. 38(3): p. 1697-1702.

22. Desta, Z., et al., Clinical significance of the cytochrome P450 2 C19 genetic polymorphism. Clin Pharmacokinet, 2002. 41(12): p. 913-58.

23. Sim, S.C., et al., A common novel CYP2C19 gene variant causes ultrarapid drug metabolism relevant for the drug response to proton pump inhibitors and antidepressants. Clin Pharmacol Ther, 2006. 79(1): p. 103-13. 
24. Shah, R.R. and D.R. Shah, Personalized medicine: is it a pharmacogenetic mirage? British Journal of Clinical Pharmacology, 2012. 74(4): p. 698-721.

25. Subraja, K., et al., Genetic polymorphisms of CYP2C19 influences the response to clopidogrel in ischemic heart disease patients in the South Indian Tamilian population. Eur J Clin Pharmacol, 2013. 69(3): p. 415-22.

26. Ibeanu, G.C., et al., Identification of new human CYP2C19 alleles (CYP2C19*6 and CYP2C19*2B) in a Caucasian poor metabolizer of mephenytoin. J Pharmacol Exp Ther, 1998. 286(3): p. 1490-5.

27. Xie, H.G., et al., CYP2C9 allelic variants: ethnic distribution and functional significance. Adv Drug Deliv Rev, 2002. 54(10): p. 1257-70.

28. Rendic, S., Summary of information on human CYP enzymes: human P450 metabolism data. Drug Metab Rev, 2002. 34(1-2): p. 83-448.

29. Roy, J.N., et al., CYP3A5 genetic polymorphisms in different ethnic populations. Drug Metab Dispos, 2005. 33(7): p. 884-7.

30. Kitada, M., et al., Significance of cytochrome P-450 (P-450 HFLa) of human fetal livers in the steroid and drug oxidations. Biochem Pharmacol, 1987. 36(4): p. 453-6.

31. Waxman, D.J., et al., Human liver microsomal steroid metabolism: identification of the major microsomal steroid hormone 6 beta-hydroxylase cytochrome P-450 enzyme. Arch Biochem Biophys, 1988. 263(2): p. 424-36.

32. Garsa, A.A., H.L. McLeod, and S. Marsh, CYP3A4 and CYP3A5 genotyping by Pyrosequencing. BMC Med Genet, 2005. 6: p. 19.

33. Thervet, E., et al., Impact of cytochrome p450 3 A5 genetic polymorphism on tacrolimus doses and concentration-to-dose ratio in renal transplant recipients. Transplantation, 2003. 76(8): p. 1233-5.

34. Zheng, Y.M., et al., Genotyping and site-directed mutagenesis of a cytochrome P450 meander Pro-X-Arg motif critical to CYP4B1 catalysis. Toxicol Appl Pharmacol, 2003. 186(2): p. 119-26.

35. Gijsen, V., et al., Age and CYP3A5 genotype affect tacrolimus dosing requirements after transplant in pediatric heart recipients. J Heart Lung Transplant, 2011. 30(12): p. 1352-9.

36. Park, K.W., et al., Amlodipine, clopidogrel and CYP3A5 genetic variability: effects on platelet reactivity and clinical outcomes after percutaneous coronary intervention. Heart, 2012. 98(18): p. 1366-72.

37. Priyadharsini, R., et al., Single nucleotide polymorphism of CYP3A5*3 contributes to clopidogrel resistance in coronary artery disease patients among Tamilian population. Molecular Biology Reports, 2014. 41(11): p. 7265-7271.

38. Suh, J.W., et al., Increased risk of atherothrombotic events associated with cytochrome P450 3 A5 polymorphism in patients taking clopidogrel. CMAJ, 2006. 174(12): p. 1715-22.

39. Kim, K.A., P.W. Park, and J.Y. Park, Effect of CYP3A5*3 genotype on the pharmacokinetics and antiplatelet effect of clopidogrel in healthy subjects. Eur J Clin Pharmacol, 2008. 64(6): p. 58997.

40. Saad, A.A., et al., Effect of cytochrome P450 3 A5 polymorphism on platelet reactivity after treatment with clopidogrel in patients scheduled for percutaneous coronary intervention. The Egyptian Heart Journal, 2011. 63(1): p. 23-31.

41. Zhu, Y. and J. Zhou, Identification of the Significant Involvement and Mechanistic Role of CYP3A4/5 in Clopidogrel Bioactivation. ACS Med Chem Lett, 2012. 3(10): p. 844-9.

42. Sachs, G., J.M. Shin, and C.W. Howden, Review article: the clinical pharmacology of proton pump inhibitors. Aliment Pharmacol Ther, 2006. 23 Suppl 2: p. 2-8.

43. Drepper, M.D., L. Spahr, and J.L. Frossard, Clopidogrel and proton pump inhibitors--where do we stand in 2012? World J Gastroenterol, 2012. 18(18): p. 2161-71.

44. Lettino, M., Inhibition of the antithrombotic effects of clopidogrel by proton pump inhibitors: facts or fancies? Eur J Intern Med, 2010. 21(6): p. 484-9. 
45. Moukarbel, G.V., et al., Gastrointestinal bleeding in high risk survivors of myocardial infarction: the VALIANT Trial. Eur Heart J, 2009. 30(18): p. 2226-32.

46. Grove, E.L., et al., Gastrointestinal events with clopidogrel: a nationwide population-based cohort study. J Gen Intern Med, 2013. 28(2): p. 216-22.

47. Depta, J.P. and D.L. Bhatt, Omeprazole and clopidogrel: Should clinicians be worried? Cleveland Clinic journal of medicine, 2010. 77(2): p. 113-116.

48. Bhatt, D.L., et al., Clopidogrel with or without Omeprazole in Coronary Artery Disease. New England Journal of Medicine, 2010. 363(20): p. 1909-1917.

49. Juurlink, D.N., et al., A population-based study of the drug interaction between proton pump inhibitors and clopidogrel. Canadian Medical Association Journal, 2009. 180(7): p. 713-718.

50. Juel, J., M. Pareek, and S.E. Jensen, The clopidogrel-PPI interaction: an updated mini-review. Curr Vasc Pharmacol, 2014. 12(5): p. 751-7.

51. Tantry, U.S., D.J. Kereiakes, and P.A. Gurbel, Clopidogrel and proton pump inhibitors: influence of pharmacological interactions on clinical outcomes and mechanistic explanations. JACC Cardiovasc Interv, 2011. 4(4): p. 365-80.

52. Gilard, M., et al., Influence of omeprazole on the antiplatelet action of clopidogrel associated with aspirin: the randomized, double-blind OCLA (Omeprazole CLopidogrel Aspirin) study. J Am Coll Cardiol, 2008. 51(3): p. 256-60.

53. Collet, J.P., et al., Cytochrome P450 2 C19 polymorphism in young patients treated with clopidogrel after myocardial infarction: a cohort study. Lancet, 2009. 373(9660): p. 309-17.

54. Simon, T., et al., Genetic determinants of response to clopidogrel and cardiovascular events. N Engl J Med, 2009. 360(4): p. 363-75.

55. leiri, I., et al., Interaction magnitude, pharmacokinetics and pharmacodynamics of ticlopidine in relation to CYP2C19 genotypic status. Pharmacogenet Genomics, 2005. 15(12): p. 851-9.

56. Chen, C.H., et al., Differential inhibitory effects of proton pump inhibitors on the metabolism and antiplatelet activities of clopidogrel and prasugrel. Biopharm Drug Dispos, 2012. 33(5): p. 278-83.

57. Agewall, S., et al., Expert position paper on the use of proton pump inhibitors in patients with cardiovascular disease and antithrombotic therapy. European Heart Journal, 2013.

58. Würtz, M., et al., The antiplatelet effect of aspirin is reduced by proton pump inhibitors in patients with coronary artery disease. Heart, 2010. 96(5): p. 368-371.

59. Charlot, M., et al., Proton pump inhibitor use and risk of adverse cardiovascular events in aspirin treated patients with first time myocardial infarction: nationwide propensity score matched study. BMJ, 2011. 342.

60. van Boxel, O.S., et al., Cardiovascular and gastrointestinal outcomes in clopidogrel users on proton pump inhibitors: results of a large Dutch cohort study. Am J Gastroenterol, 2010. 105(11): p. 2430-6; quiz 2437.

61. Giusti, B., et al., Relation of cytochrome P450 2 C19 loss-of-function polymorphism to occurrence of drug-eluting coronary stent thrombosis. Am J Cardiol, 2009. 103(6): p. 806-11.

62. Harmsze, A.M., et al., CYP2C19*2 and CYP2C9*3 alleles are associated with stent thrombosis: a case-control study. Eur Heart J, 2010. 31(24): p. 3046-53.

63. Harmsze, A.M., et al., Combined influence of proton-pump inhibitors, calcium-channel blockers and CYP2C19*2 on on-treatment platelet reactivity and on the occurrence of atherothrombotic events after percutaneous coronary intervention. J Thromb Haemost, 2011. 9(10): p. 1892-901.

64. Malek, L.A., et al., Coexisting Polymorphisms of P2Y12 and CYP2C19 Genes as a Risk Factor for Persistent Platelet Activation With Clopidogrel. Circulation Journal, 2008. 72(7): p. 11651169.

65. Oh, I.-Y., et al., Association of cytochrome P450 2C19*2 polymorphism with clopidogrel response variability and cardiovascular events in Koreans treated with drug-eluting stents. Heart, 2012. 98(2): p. 139-144. 
66. Ono, T., et al., Determination of cut-off levels for on-clopidogrel platelet aggregation based on functional CYP2C19 gene variants in patients undergoing elective percutaneous coronary intervention. Thrombosis Research. 128(6): p. e130-e136.

67. Sawada, T., et al., Impact of Cytochrome P450 2C19*2 Polymorphism on Intra-Stent Thrombus After Drug-Eluting Stent Implantation in Japanese Patients Receiving Clopidogrel. Circulation Journal, 2011. 75(1): p. 99-105.

68. Shuldiner, A.R., et al., Association of cytochrome P450 2C19 genotype with the antiplatelet effect and clinical efficacy of clopidogrel therapy. JAMA, 2009. 302(8): p. 849-57.

69. Sibbing, D., et al., Cytochrome P450 2 C19 loss-of-function polymorphism and stent thrombosis following percutaneous coronary intervention. Eur Heart J, 2009. 30(8): p. 916-22.

70. Sibbing, D., et al., Cytochrome 2C19*17 allelic variant, platelet aggregation, bleeding events, and stent thrombosis in clopidogrel-treated patients with coronary stent placement. Circulation, 2010. 121(4): p. 512-8.

71. Sibbing, D., et al., No association of paraoxonase-1 Q192R genotypes with platelet response to clopidogrel and risk of stent thrombosis after coronary stenting. European Heart Journal, 2011. 32(13): p. 1605-1613.

72. Trenk, D., et al., Cytochrome P450 2 C19 681G>A polymorphism and high on-clopidogrel platelet reactivity associated with adverse 1-year clinical outcome of elective percutaneous coronary intervention with drug-eluting or bare-metal stents. J Am Coll Cardiol, 2008. 51(20): p. 1925-34.

73. Yan, S.D., et al., The value of combining CYP2C19*2 polymorphism with classic risk factors in prediction of clinical prognosis in acute coronary syndrome patients. Cardiology, 2011. 119(1): p. 15-20.

74. Mega, J.L., et al., Cytochrome $p-450$ polymorphisms and response to clopidogrel. N Engl J Med, 2009. 360(4): p. 354-62.

75. Wallentin, L., et al., Effect of CYP2C19 and ABCB1 single nucleotide polymorphisms on outcomes of treatment with ticagrelor versus clopidogrel for acute coronary syndromes: a genetic substudy of the PLATO trial. Lancet, 2010. 376(9749): p. 1320-8.

76. Bouman, H.J., et al., Paraoxonase-1 is a major determinant of clopidogrel efficacy. Nat Med, 2011. 17(1): p. 110-116.

77. Tello-Montoliu, A., et al., Influence of CYP2C19 polymorphisms in platelet reactivity and prognosis in an unselected population of non ST elevation acute coronary syndrome. Rev Esp Cardiol (Engl Ed), 2012. 65(3): p. 219-26.

78. Pare, G., et al., Effects of CYP2C19 genotype on outcomes of clopidogrel treatment. N Engl J Med, 2010. 363(18): p. 1704-14.

79. Kang, Y.S., et al., The CYP3A4*18 Genotype in the Cytochrome P450 3A4 Gene, a Rapid Metabolizer of Sex Steroids, Is Associated With Low Bone Mineral Density. Clinical Pharmacology \& Therapeutics, 2009. 85(3): p. 312-318.

80. Keshava, C., E.C. McCanlies, and A. Weston, CYP3A4 polymorphisms--potential risk factors for breast and prostate cancer: a HuGE review. Am J Epidemiol, 2004. 160(9): p. 825-41.

81. Wang, R.W., et al., Human cytochrome P-450 3A4: in vitro drug-drug interaction patterns are substrate-dependent. Drug Metab Dispos, 2000. 28(3): p. 360-6.

82. Dai, D., et al., Identification of Variants of CYP3A4 and Characterization of Their Abilities to Metabolize Testosterone and Chlorpyrifos. Journal of Pharmacology and Experimental Therapeutics, 2001. 299(3): p. 825-831.

83. Chowbay, B., S. Zhou, and E.J. Lee, An interethnic comparison of polymorphisms of the genes encoding drug-metabolizing enzymes and drug transporters: experience in Singapore. Drug Metab Rev, 2005. 37(2): p. 327-78.

84. Angiolillo, D.J., et al., Influence of aspirin resistance on platelet function profiles in patients on long-term aspirin and clopidogrel after percutaneous coronary intervention. Am J Cardiol, 2006. 97(1): p. 38-43. 
85. Lau, W.C., et al., Contribution of hepatic cytochrome P450 3A4 metabolic activity to the phenomenon of clopidogrel resistance. Circulation, 2004. 109(2): p. 166-71.

86. Giusti, B., et al., Cytochrome P450 2C19 loss-of-function polymorphism, but not CYP3A4 IVS10 $+12 G / A$ and P2Y12 T744C polymorphisms, is associated with response variability to dual antiplatelet treatment in high-risk vascular patients. Pharmacogenet Genomics, 2007. 17(12): p. 1057-64.

87. Fontana, P., et al., Influence of CYP2C19 and CYP3A4 gene polymorphisms on clopidogrel responsiveness in healthy subjects. J Thromb Haemost, 2007. 5(10): p. 2153-5.

88. Dunn, S.P., et al., Abstract 3999: Baseline Proton Pump Inhibitor Use is Associated with Increased Cardiovascular Events With and Without the Use of Clopidogrel in the CREDO Trial. Circulation. 2008; 118: S_815.

89. Charlot, M., et al., Proton-pump inhibitors are associated with increased cardiovascular risk independent of clopidogrel use: a nationwide cohort study. Ann Intern Med, 2010. 153(6): p. 378-86.

90. Ho, P., et al., RIsk of adverse outcomes associated with concomitant use of clopidogrel and proton pump inhibitors following acute coronary syndrome. JAMA, 2009. 301(9): p. 937-944.

91. Banerjee, S., et al., Effect of Concomitant Use of Clopidogrel and Proton Pump Inhibitors After Percutaneous Coronary Intervention. American Journal of Cardiology, 2011. 107(6): p. 871878.

92. Ray, W.A., et al., Outcomes With Concurrent Use of Clopidogrel and Proton-Pump InhibitorsA Cohort Study. Annals of Internal Medicine, 2010. 152(6): p. 337-345.

93. Rassen, J.A., et al., Cardiovascular Outcomes and Mortality in Patients Using Clopidogrel With Proton Pump Inhibitors After Percutaneous Coronary Intervention or Acute Coronary Syndrome. Circulation, 2009. 120(23): p. 2322-2329.

94. Simon, T., et al., Clinical Events as a Function of Proton Pump Inhibitor Use, Clopidogrel Use, and Cytochrome P450 2C19 Genotype in a Large Nationwide Cohort of Acute Myocardial Infarction: Results From the French Registry of Acute ST-Elevation and Non-ST-Elevation Myocardial Infarction (FAST-MI) Registry. Circulation, 2011. 123(5): p. 474-482.

95. Harjai, K.J., et al., Six-Month Outcomes with or without Proton-Pump Inhibitors after Successful PCl: Insights from the Guthrie PCI Registry. Journal of the American College of Cardiology, 2010. 55(10s1): p. A179.E1675-A179.E1675. 
Table 1: Ethnic distribution of CYP2C19*2 and CYP2C19*3 alleles (calculated using 1000 genomes data).

\begin{tabular}{|c|c|c|c|c|c|c|c|}
\hline \multicolumn{4}{|c|}{ Distribution of the Allele rs4244285 (CYP2C19*2) } & \multicolumn{4}{|c|}{ Distribution of the Allele rs4986893 (CYP2C19*3) } \\
\hline & G:0.5A:0.5 & G:0A:1 & G: 1A:0 & & G:0.5A:0.5 & G:0A:1 & G: $1 A: 0$ \\
\hline American & 19.60 & 0.85 & 79.55 & American & 0.00 & 0.00 & 100.00 \\
\hline European & 26.53 & 1.19 & 72.28 & European & 0.00 & 0.00 & 100.00 \\
\hline African & 26.91 & 3.44 & 69.66 & African & 0.45 & 0.00 & 99.55 \\
\hline Asian & 44.10 & 11.10 & 44.80 & Asian & 6.64 & 0.10 & 93.26 \\
\hline \multicolumn{4}{|l|}{ Distribution in Asia } & \multicolumn{4}{|c|}{ Distribution in Asia } \\
\hline North Asian & 46.99 & 7.38 & 45.63 & North Asian & 10.68 & 0.19 & 89.13 \\
\hline South Asian & 41.09 & 14.98 & 43.93 & South Asian & 2.43 & 0.00 & 97.57 \\
\hline \multicolumn{4}{|c|}{ Distribution in South Asia } & \multicolumn{4}{|c|}{ Populations within North Asia } \\
\hline North_South_Asian & 37.85 & 14.24 & 47.92 & Japanese, Tokyo & 12.50 & 0.96 & 86.54 \\
\hline South Asian & 45.63 & 16.02 & 38.35 & $\begin{array}{l}\text { Chinese Dai in } \\
\text { Xishuangbann }\end{array}$ & 15.15 & 0.00 & 84.85 \\
\hline \multicolumn{4}{|c|}{ Populations in South Asia } & $\begin{array}{l}\text { Southern Han } \\
\text { Chinese }\end{array}$ & 9.26 & 0.00 & 90.74 \\
\hline South Indian Telugu & 44.66 & 14.56 & 40.78 & $\begin{array}{l}\text { Han Chinese in } \\
\text { Beijing }\end{array}$ & 8.74 & 0.00 & 91.26 \\
\hline Srilankan Tamil & 46.60 & 17.48 & 35.92 & $\begin{array}{l}\text { Kinh in Ho Chi } \\
\text { Minh City, Vietna }\end{array}$ & 7.92 & 0.00 & 92.08 \\
\hline
\end{tabular}

The allele "G" is the actual reference allele at that genomic position. The allele "A" represents the alternate allele at that location.

The summary in this case represents the: 1) The proportion of patients with allele $1(G)$ [i.e. G: 1A:0], 2) The proportion of patients with half of allele $1(G)$ and half of allele $2(A)$. [i.e. G:0.5A:0.5] 
Table 2: Ethnic distribution of CYP2C19*2B allele (calculated using 1000 genomes data).

\begin{tabular}{llc}
\hline \multicolumn{4}{c}{ Distribution of the Allele rs17878459 } & (CYP2C19*2B) \\
\hline Asian & G:0.5 C:0.5 & G: 1 C: \\
\hline African & 0.00 & 100.00 \\
\hline American & 0.75 & 99.25 \\
\hline European & 1.14 & 98.86 \\
\hline Distribution in Europe & 7.13 & 92.87 \\
\hline Finnish in Finland & 12.12 & 87.88 \\
\hline British in England and Scotland & 9.78 & 90.22 \\
\hline Utah residents with Northern and Western European & 5.05 & 94.95 \\
ancestry & & 95.33 \\
\hline Iberian populations in Spain & 4.67 & 95.37 \\
\hline Tuscany in Italy & 4.63 & \\
\hline
\end{tabular}

The allele "G" is the actual reference allele at that genomic position. The allele " $C$ " represents the alternate allele at that location. The summary in this case represents the:1) The proportion of patients with allele $1(G)$ [i.e. G:1 C:0], 2), the proportion of patients with half of allele 1 (G) and half of allele 2 (C). [i.e. G:0.5C:0.5] 
Table 3: Studies on interactions between CYP2C19 and its variants and cardiovascular events

\begin{tabular}{|c|c|c|c|c|c|}
\hline $\begin{array}{l}\text { Ethnic } \\
\text { Population }\end{array}$ & $\begin{array}{c}\mathbf{N}^{\circ} \text { of } \\
\text { Participants }\end{array}$ & CYP2C19* Alleles & $\begin{array}{l}\text { Follow up } \\
\text { period } \\
\text { (months) }\end{array}$ & $\begin{array}{l}\text { Association } \\
\text { with CYP2C19 } \\
\text { polymorphism }\end{array}$ & References \\
\hline Caucasian & 259 & $* 2, * 3, * 4, * 5, * 6$ & 12 & Yes & [53] \\
\hline Caucasian & 772 & $* 2$ & 6 & Yes & [61] \\
\hline Caucasian & 596 & $* 2, * 3$ & NA & Yes & [62] \\
\hline Caucasian & 725 & $* 2, * 17$ & 12 & Yes & [63] \\
\hline Polish & 105 & $* 2$ & 48 & Yes & [64] \\
\hline Korean & 2146 & $* 2$ & 12 & Yes & [65] \\
\hline Japanese & 202 & $* 2, * 3$ & 12 & Yes & [66] \\
\hline Japanese & 100 & $* 2$ & 8 & Yes & [67] \\
\hline Amish & 429 & $* 2$ & 12 & Yes & [68] \\
\hline German & 2485 & $* 2$ & 1 & Yes & [69] \\
\hline German & 1525 & $* 17$ & 1 & Yes & [므] \\
\hline German & 1566 & $* 2$ & - & Yes & [71] \\
\hline French & 2208 & $* 2, * 3, * 4, * 5, * 17$ & 12 & Yes & [54] \\
\hline German & 797 & $* 2$ & 12 & Yes & [72] \\
\hline Chinese & 497 & $* 2$ & 20 & Yes & [73] \\
\hline Caucasian & 1477 & $* 2, * 3, * 4, * 5, * 8$ & $6-15$ & Yes & [74] \\
\hline Caucasian & 10285 & $\begin{array}{l}* 2, * 3, * 4, * 5, * 6, * 7, * 8, \\
* 17\end{array}$ & 12 & Yes & [75] \\
\hline Caucasian & 4862 & $* 2, * 3, * 17$ & 28 & Yes & [ㄷ] \\
\hline Caucasian & 471 & $* 2, * 17$ & 12 & No & {$[\underline{76}, \underline{77}]$} \\
\hline Caucasian & 6215 & $* 2, * 3, * 17$ & $3-12$ & No & [78] \\
\hline
\end{tabular}


Table 4: Ethnic distribution of CYP3A4/5 alleles.

\begin{tabular}{|c|c|c|c|c|c|}
\hline Allele & Mutation & Effect on probe drugs & $\begin{array}{c}\text { Caucasian } \\
\text { (\%) }\end{array}$ & $\begin{array}{l}\text { Asian } \\
\text { (\%) }\end{array}$ & $\begin{array}{c}\text { African } \\
\text { (\%) }\end{array}$ \\
\hline CYP3A4*1 & Wild type & Normal & NA & NA & NA \\
\hline CYP3A4*2 & S222P & $\begin{array}{l}\text { Substrate dependent } \\
\text { altered kinetics }\end{array}$ & 2.7 & 0 & 0 \\
\hline CYP3A $4 * 4$ & I118V & Decreased & NA & 1 & NA \\
\hline CYP3A4*8 & R130Q & Decreased & 1.41 & NA & 4 \\
\hline CYP3A4*18 & L293P & $\begin{array}{l}\text { Substrate dependent } \\
\text { altered kinetics }\end{array}$ & NA & $18-20$ & NA \\
\hline CYP3A5*1 & Wild type & Normal & $8-14$ & $8.3-12.2$ & 45 \\
\hline CYP3A5*2 & T398N & Decreased & $5-10$ & NA & NA \\
\hline CYP3A5*3 & $6986 \mathrm{~A}>\mathrm{G}$ & Decreased & $77-93$ & 77 & $27-50$ \\
\hline CYP3A5*4 & Q200R & Decreased & NA & NA & NA \\
\hline CYP3A5*8 & $\mathrm{R} 28 \mathrm{C}$ & Decreased & NA & NA & NA \\
\hline
\end{tabular}

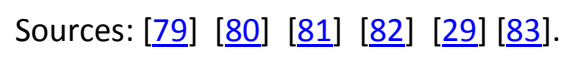


Table 5: Ethnic distribution of CYP3A5*3 (computed using 1000 genomes data)

\begin{tabular}{cccc}
\hline Distribution of the Allele rs776746 (CYP3A5*3) & C:0.5T:0.5 & C: 0T:1 & C: 1T: 0 \\
\hline American & 29.11 & 5.76 & 65.13 \\
\hline European & 10.54 & 0.40 & 89.07 \\
\hline African & 28.74 & 67.62 & 3.63 \\
\hline Asian & 41.89 & 9.97 & 48.14 \\
\hline North_Asian & 41.47 & 7.94 & 50.60 \\
\hline South_Asian & 42.33 & 12.07 & 45.60
\end{tabular}

The allele "C" is the actual reference allele at that genomic position. The allele "T" represents the alternate allele at that location.

The summary in this case represents:1) The proportion of patients with allele 1 (C) [i.e. C:1T:0]

2) The proportion of patients with half of allele 1 (C) and half of allele 2 (T). [i.e. C: 0.5T:0.5] 
Table 6: Studies showing association/no association between CYP3A4/3A5 and clopidogrel responsiveness.

Association between CYP3A4/3A5 and clopidogrel responsiveness

\begin{tabular}{|c|c|c|c|c|}
\hline Reference & $\begin{array}{l}\text { Ethnic } \\
\text { population }\end{array}$ & $\begin{array}{l}\text { Total } \\
\text { participants }\end{array}$ & $\begin{array}{l}\text { CYP3A4/3A5* } \\
\text { alleles genotyped } \\
\text { and reported }\end{array}$ & $\begin{array}{l}\text { Association with } \\
\text { CYP3A4 /5 } \\
\text { polymorphism }\end{array}$ \\
\hline [84] & Caucasian & 82 & $3 \mathrm{~A} 4 * 1 \mathrm{~B}, 3 \mathrm{~A} 4 * 3$ & Yes \\
\hline [ㄷ] & Caucasian & 67 & NA & Yes \\
\hline$[\underline{36}]$ & Caucasian & 1258 & $3 A 5 * 3=749$ & Yes \\
\hline$[\underline{38}]$ & Caucasian & 32 & $3 A 5 * 3=16$ & Yes \\
\hline$[\underline{38}]$ & Caucasian & 348 & NA & Yes \\
\hline \multicolumn{5}{|c|}{ Absence of association between CYP3A4/3A5 and clopidogrel responsiveness } \\
\hline$[\underline{86}]$ & Italian & 1419 & NA & No \\
\hline [87] & Caucasian & 94 & NA & No \\
\hline [드] & Caucasian & 112 & $3 \mathrm{~A} 4 * 1 \mathrm{~B}, 3 \mathrm{~A} 4 * 1 \mathrm{G}$ & No \\
\hline$[\underline{40}]$ & Egyptian & 45 & $3 A 5 * 3$ & No \\
\hline
\end{tabular}


Table 7: Clinical trials showing the effect of co-administration of clopidogrel with proton pump inhibitors.

\begin{tabular}{|c|c|c|c|}
\hline Study & $\begin{array}{c}\text { Total } \\
\text { patients }\end{array}$ & Primary outcome & Results \\
\hline$[\underline{60}]$ & 18,139 & $\begin{array}{l}2 \text { yr composite endpoint of ACS, } \\
\text { stroke and any cause death }\end{array}$ & $\begin{array}{l}\text { Increased risk of composite endpoint, } \\
\text { myocardial infarction and unstable angina } \\
\text { pectoris }\end{array}$ \\
\hline$[\underline{49}]$ & 13,636 & 90-d readmission for acute $\mathrm{MI}$ & $\begin{array}{l}\text { Increased risk of reinfarction in } \\
\text { PPI users except pantoprazole }\end{array}$ \\
\hline [88] & 2116 & $\begin{array}{l}28 \mathrm{~d} \text { death, } \mathrm{MI} \text {, urgent target } \\
\text { vessel re-vascularization } 1 \mathrm{yr} \\
\text { death, } \mathrm{Ml} \text { or stroke }\end{array}$ & $\begin{array}{l}\text { Increased risk for adverse cardiovascular } \\
\text { outcome regardless of clopidogrel use }\end{array}$ \\
\hline$[\underline{89}]$ & 56,406 & $\begin{array}{l}1 \text { yr composite end point of } \mathrm{MI} \\
\text { stroke or cardiovascular death }\end{array}$ & $\begin{array}{l}\text { Increased risk for adverse cardiovascular } \\
\text { outcomes in PPI users regardless of } \\
\text { clopidogrel use }\end{array}$ \\
\hline [48] & 3873 & $\begin{array}{l}\text { Mean } 133 \text { d- composite safety } \\
\text { endpoint of cardiovascular } \\
\text { death, MI, coronary } \\
\text { revascularization }\end{array}$ & $\begin{array}{l}\text { No difference between PPI and placebo } \\
\text { Group. Clopidogrel plus aspirin was not } \\
\text { significantly more effective than aspirin alone }\end{array}$ \\
\hline$[\underline{90}]$ & 8205 & $\begin{array}{l}3 \text { yr death or re-hospitalization } \\
\text { for ACS }\end{array}$ & $\begin{array}{l}\text { Increased risk for death or re-hospitalization } \\
\text { in PPI use }\end{array}$ \\
\hline [91] & 23,200 & 6-yr MACE & No increased risk for MACE in PPI users \\
\hline$[\underline{92}]$ & 20,596 & $\begin{array}{l}1 \text { yr composite end point of } \\
\text { ACS, stroke or cardiovascular } \\
\text { death }\end{array}$ & $\begin{array}{l}\text { No increased risk for serious cardiovascular } \\
\text { disease in PPI users }\end{array}$ \\
\hline$[\underline{93}]$ & 18,565 & $\begin{array}{l}180 \mathrm{~d} \text { composite end point of } \\
\text { hospitalization for } \mathrm{MI} \text { and } \mathrm{PCl} \text { or } \\
\text { death of any cause }\end{array}$ & $\begin{array}{l}\text { No increased risk for serious cardiovascular } \\
\text { disease in PPI users }\end{array}$ \\
\hline$[\underline{94}]$ & 2744 & $\begin{array}{l}\text { In hospital and 1-yr death, } \\
\text { reinfarction or stroke }\end{array}$ & $\begin{array}{l}\text { No increased risk of cardiovascular } \\
\text { events and mortality in PPI users }\end{array}$ \\
\hline$[\underline{95}]$ & 2651 & 6-mo MACE & No increased risk for MACE in PPI users \\
\hline
\end{tabular}

Legend; PPI: Proton Pump Inhibitors; yr: year; mo: month; d: day; ACE: Acute Coronary Syndrome; MACE: Major Adverse Cardiac Events. 
*Email: khaled.moustafa@gmail.com 